\title{
Control Method of the DFIG Connected to a DC Link through a Diode Bridge
}

\author{
G. D. Marques ${ }^{1}$, M. F. Iacchetti $^{2}$ \\ ${ }^{1}$ INESC-ID, IST, University of Lisbon, Lisbon, Portugal \\ ${ }^{2}$ Department of Electrical Engineering, Politecnico di Milano, Milano, Italy \\ Email: gil.marques@ist.utl.pt and matteo.iacchetti@polimi.it
}

Received February, 2013

\begin{abstract}
This paper presents a control method for the Doubly-fed Induction Generator connected to a dc link through a diode bridge on the stator. In this system, the rotor is fed, at the slip frequency, by a PWM electronic converter and the stator is directly connected to the dc link using a simple diode bridge. The cost of power electronics is reduced in this system when compared with the classic DFIG machine because the system uses less one PWM inverter and additionally it uses a diode bridge. The application in mind is for microgrids. Microgrids need several elements that should work together. The usual way to connect these elements is to use power electronic devices in a common dc link. This paper presents a new form for the DFIG for this application and presents a control system for the inner control loop. Simulation and experimental results show that the system can work acceptably using a stator frequency near the rated frequency of the machine.
\end{abstract}

Keywords: Doubly-fed Induction Generator; Dc Link; Control

\section{Introduction}

A microgrid can be defined as a part of a distribution network embedding multiple distributed generation as renewable energy sources like photovoltaic panels, small wind turbines etc., and storage systems. Most commonly used energy storage devices in a microgrid are batteries, supercapacitors, flywheels, and fuel cells. This type of energy storage is termed as distributed storage and the energy storage devices are termed as distributed storage devices. These systems, with local loads, can be disconnected from the upstream network under emergency conditions [1, 2].

The integration of renewable energy sources into a microgrid poses a challenge because their output is intermittent and variable and, in principle, requires energy storage to enable time-shift between energy production and consumption. Several devices should be connected together and this brings problems.

The power connection between microgrid components, i.e. distributed generation sources, storages and loads, can be done through a direct current (dc) link or an alternating current (ac) link. In general, today these different devices are Power Electronics controlled and each one of these converters needs a dc link [3-9]. If the same dc link is used considerable savings can be obtained.

The Doubly-fed Induction Generator (DFIG) is a well-known system. It has been applied to wind power extraction plants working in generator mode converting mechanical energy into electrical energy at adjustable speed. Its main advantage is that, for a small range of speed adjustment, it needs power electronics devices rated to a fraction of the rating power of the wind turbine. In this system, the stator is directly connected to the network, and the rotor is connected to the network by an ac/dc/ac frequency converter $[10,11]$.

The usual application of the DFIG is connected to the ac mains. There are many applications and this system can now be considered as mature technology.

There are also other applications where the DFIG is used in standalone operation [11,12]. In this case there is no ac network that imposes the stator frequency.

This paper presents a new structure for the DFIG and one possible control system. The purpose is to use it connected to a dc link in applications like microgrids. This system brings considerable benefits because the cost of power electronics is reduced as only a PWM ac/dc converter is necessary. The purpose of the control system is to regulate the DFIG torque and the stator frequency near the rated frequency of the machine.

Section II presents the structure of the system. It uses only an ac/dc PWM converter connecting the rotor to the dc link and a simple diode bridge connecting the stator to the dc link. The modeling and steady state laws are presented in section III. The structure of the control system 
proposed in this paper is presented in section IV. Simulations, section V, and experimental results, section VI, show that the system can be applied in microgrids operating as generator in small wind turbines.

\section{The Structure of the System}

If the generator is to be connected to a dc link, only an ac/dc converter is needed. The stator is connected to the dc link using a diode bridge. The structure of the system is presented in Figure 1. This figure shows also the conventions used in this paper. The active power on the stator terminals is considered positive when it flows from the machine to the rectifier. However on the rotor a reverse convention is used. The torque is considered negative in the operation as generator. Because a diode bridge is used in the stator terminals, only generator mode operation is possible.

\section{Modeling and Steady State}

To represent the induction machine in steady state, the $\Gamma$ equivalent circuit is used. It is shown in Figure 2.

According to the conventions adopted in Figure 2:

$$
\bar{I}_{2}=\bar{I}_{1}+\bar{I}_{m}
$$

\subsection{Steady-state Simplified Model}

The correspondent phasor diagram for the first harmonic is shown in Figure 3. In this case the phase-shift due to overlapping of the diodes during commutation, imposed by the diode bridge between the stator voltage and first harmonic of the current is neglected. This is only the first approach to better understand the system. Experimental results will show that this simplification is acceptable.

The most used control system of the DFIG is the stator flux orientation. In this methodology, the control is performed in the rotor circuits in the reference frame oriented with the stator flux space vector. In this paper, an attempt to control the system in a similar way will be made. Using this methodology, the diagram shown in Figure $\mathbf{3}$ is obtained, where impressed rotor current are assumed. In the case of Figure 3 the following relations involving the stator flux linkage $\psi_{s}$, the stator circular frequency $\omega_{s}$ and the voltages and currents can be written:

$$
\begin{aligned}
& I_{m}=I_{r d} \quad ; \quad I_{1}=I_{r q} \\
& \psi_{s}=L_{s} I_{m} \\
& E=\omega_{s} \psi_{s}=\omega_{s} L_{s} I_{m}=\omega_{s} L_{s} I_{r d} \\
& U_{1}=E-r_{1} I_{1}
\end{aligned}
$$

The active power in the stator is:

$$
P_{1}=3 U_{1} I_{1}=3 U_{1} I_{r q}
$$

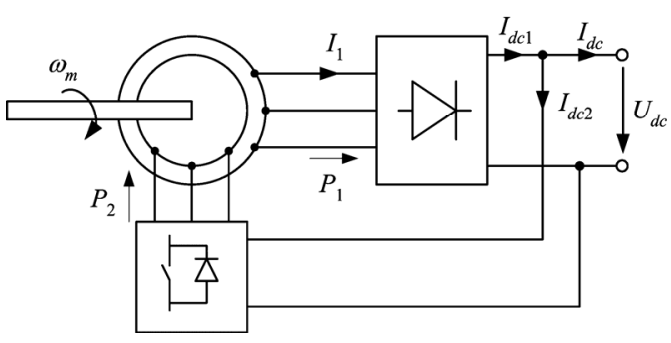

Figure 1. Structure of the DFIM-DC.

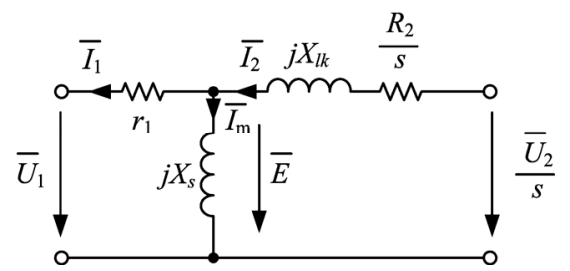

Figure 2. $\Gamma$ Equivalent circuit of the induction machine.

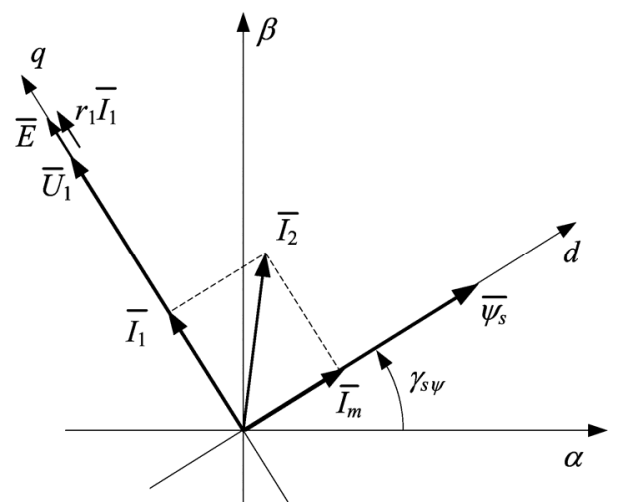

Figure 3. Phasor diagram without current shift.

So, it is possible to conclude:

- To control the voltage use $\omega_{s}$ or $\mathrm{I}_{\mathrm{rd}}$

- To control stator current use $\mathrm{I}_{\mathrm{rq}}$

- To control stator power use $\mathrm{I}_{\mathrm{rd}} \times \mathrm{I}_{\mathrm{rq}}$

This will be true only if the reference frame is appropriately oriented with the stator flux. The diode bridge gives two constraints, that is:

$$
I_{r d}>0 ; I_{r q}>0
$$

All the well known considerations concerning the rating of the rotor side inverter hold also in this case, in particular the rotor power is related to the slip by:

$$
P_{2} \approx s P_{1}
$$

If we depict with $n_{12}$ the stator/rotor turn ratio of the DFIG and with $U_{1 n}$ the rated line-to-line stator voltage, the $r m s$ value of the rated line-to line rotor voltage $U_{2 n}$ equals

$$
U_{2 n}=\frac{|s|_{\max }}{n_{12}} U_{1 n}=\frac{|s|_{\max }}{n_{12}} \frac{U_{d c}}{\sqrt{2}} .
$$

In Equation (6), the relation $U_{d c} \approx \sqrt{2} U_{1 n}$ has been con- 
sidered as roughly valid. The same relation holds for the maximum rms line-to-line ac voltage which can be obtained at the rotor side by the space vector modulation (i.e. $U_{2 n}=U_{d c} / \sqrt{2}$ ). Replacing this relation in Equation (6) yields

$$
n_{12} \cong|s|_{\max }=0.33 \text {, }
$$

where a typical range of \pm 0.33 for the slip $s$ has been assumed. We conclude that a stator/rotor turn ratio roughly equal to 0.33 allows the rotor converter and the stator diode rectifier to share the same dc-bus.

\subsection{Consideration of Overlapping of the Diodes}

It is well known that overlapping diode commutations happen in a diode bridge when a significant amount of power is transferred to the dc bus [14, 15]. This phenomenon is mainly due to the series ac inductance and in this case it has important consequences because it reduces the effects of the harmonics on the DFIG. The ac inductance is here represented by the leakage inductance (20\% in large machines). It produces also a little phase shift between the first harmonics of stator voltage and current: however such angle is normally small, even with high commutation (overlapping) angles [13, 15]. Thus, in this paper, this phase shift will be neglected. This approximation will be verified in the experimental results. On the contrary, the commutation angle will be significant and it will allow to drops the harmonic content in the stator currents and then also the torque ripple.

\section{The Structure of the Control System}

\subsection{Objectives of the Control System}

The dc current and voltage are the two output variables of this generator system. It is not possible to control both because they are not independent variables: the dc link imposes a constraint (relation) between them. In this paper it is assumed that the purpose of this system is to be connected to a dc link with constant dc voltage. In this case the dc link voltage is constant, and it is supposed that it will be controlled by other means, not from the DFIG.

The first objective of the system is to control the speed allowing its adjustment to the conditions of the wind turbine. This is done with a speed controller, which will operate in the reference torque. So the inner control system is a torque control. If there were no torque and speed controllers it is necessary the speed to be controlled by the turbine connected to the generator. This is normally not the case.

Because there is now a diode bridge, the frequency of the stator is no more imposed by ac mains, whereas the stator voltage is imposed by the Diode Bridge and dc link.
This results in a constant relation between the stator frequency and the stator flux. In this control system the objective is to control the stator frequency near the rated value of the machine. With this assumption the rated power is guaranteed, and the stator flux will have appropriate values.

The control system should have the set point rotor currents $I_{r d}{ }^{*}$ and $I_{r q}{ }^{*}$ (in a field oriented reference) as inputs, that will helps to drive the reference frame at rated frequency and control the torque. The control method is not the traditional stator FOC. In fact, the system measures the error between the reference frame where the control is performed and the stator flux and corrects this difference dynamically.

\subsection{Reference Frame Stator Angle Determination}

Field orientation is based on reference frame transformations. Being the control system presented in the rotor, and being $\gamma_{s}$ the reference position for the reference frame where the control is performed, the transformation angle is the slip position angle defined as:

$$
\gamma_{s r}=\gamma_{s}-\gamma_{m} .
$$

The angle $\gamma_{m}$ is the rotor position angle. Because $\gamma_{m}$ can be measured, or estimated using sensorless methods, the problem of reference frame determination reduces to determine $\gamma_{s}$. The FOC principle states that this should be the stator flux position angle $\gamma_{s \psi}$. Such an angle can be calculated by a stator flux estimator based on the integration of the stator electromotive forces.

However in this case it is necessary to drive the stator flux at $50 \mathrm{~Hz}$ approximately, because it is not guaranteed that it will rotate at the required frequency. The first proposed approach is shown in Figure 4.

The reference angle $\gamma_{s}^{*}$ is obtained integrating a constant frequency of $\omega_{s}$; then $\gamma_{s}^{*}$ is corrected with $\varepsilon_{p}$ obtained with a low pass filter whose input is the difference $\delta$ between the actual stator flux position $\gamma_{s \psi}$ and the desired stator flux position $\gamma_{\mathrm{s}}$. If this angle $\delta$ is maintained small, one can conclude that the system works approximately in field orientation. The parameters of this system are the gain $k_{s}$ and the time constant $\tau$.

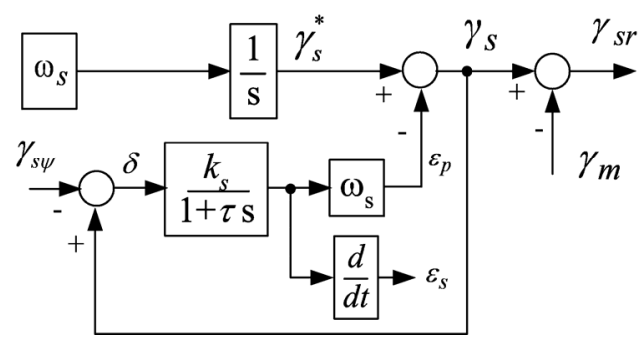

Figure 4. System to obtain the slip angle $\gamma_{\mathrm{sr}}$. 
The complete control scheme is shown in Figure 5: notice that the set point $I_{r d}{ }^{*}$ of the $d$-axis rotor current is a degree of freedom in this scheme, whereas $I_{r q}{ }^{*}$ controls the torque.

The implementation of the method proposed in Figure 4, is based in using the sine of the angle $\delta$ : in fact, $\sin \delta$ measures the deviation from FOC methodology. The position errors and speed errors are defined in the block diagram of Figure $\mathbf{4}$ as

$$
\varepsilon_{p}=\gamma_{s}^{*}-\gamma_{s}(\mathrm{rad}) ; \varepsilon_{s}=\omega_{s}-\omega_{s \psi} \text { (р.u.) }
$$

The position error $\varepsilon_{p}$ is of no importance, whereas its derivative $\varepsilon_{s}$ measures the frequency error with respect to the set point.

\subsection{Additional Adjustment of the D-axis Rotor Current Reference}

The second approach uses an additional adjustment of the $d$-axis current component with a PI controller whose input is $\sin \delta$. The block diagram is presented in Figure 6.

\section{Simulation Results}

In this section some simulation results are presented for illustrating the behavior of the system controlled with the method proposed in this paper. The parameters of the DFIG are reported in the Appendix.

Using the trial and error methodology the values of $k_{s}=1$ and $\tau=0.5 \mathrm{sec}$ were obtained. The system has shown to be very robust to the parameters. A large deviation conducts to a small change in its behavior.

\subsection{Using Only the Reference Angle Determination System}

Figures 7 to 9 show the results of the first control approach.

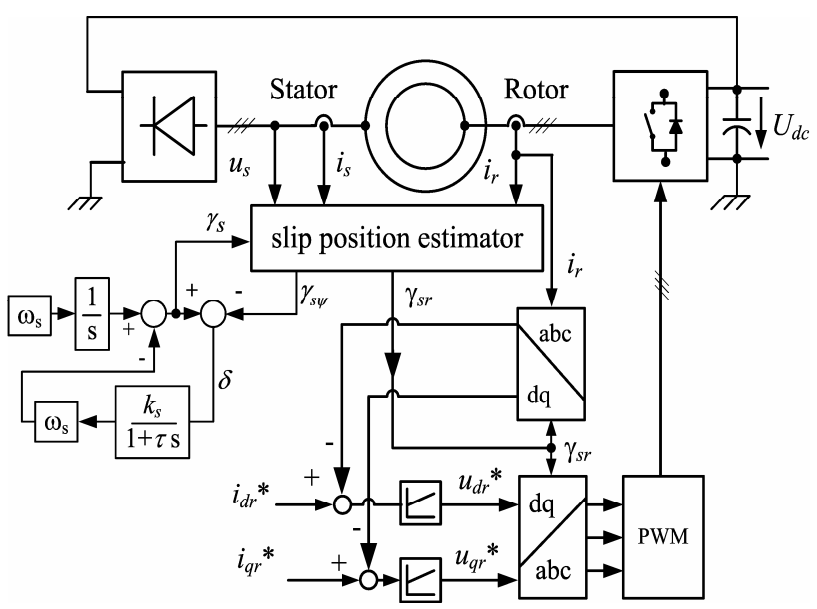

Figure 5. Control structure using a low pass filter in the synchronizing loop.

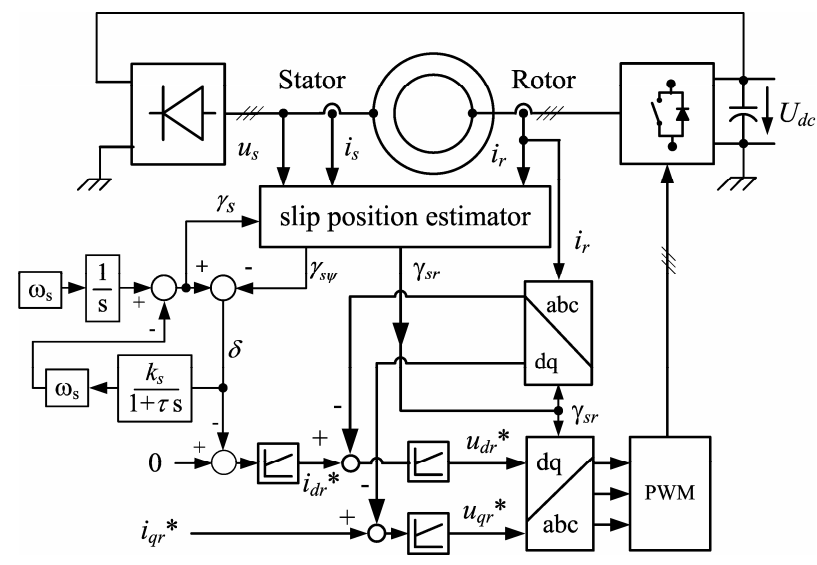

Figure 6. Control structure using a low pass filter in the synchronizing loop and an additional PI controller to adjust the d-axis reference rotor current.
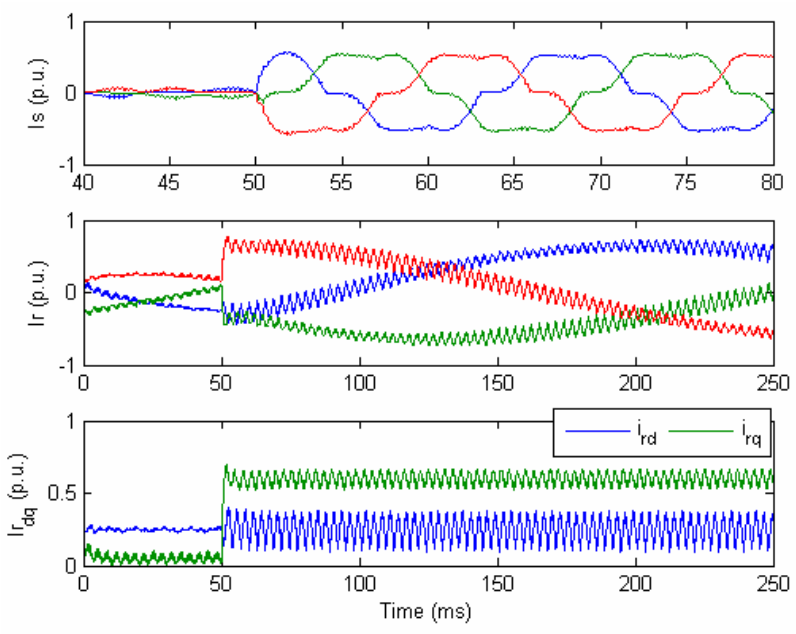

Figure 7. Stator and rotor currents.
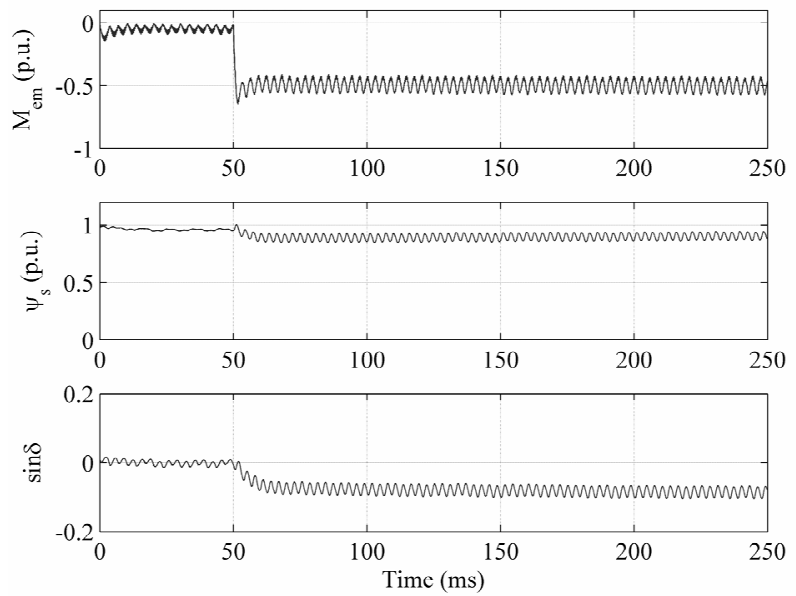

Figure 8. Torque, stator flux and $\sin \delta$.

The $d$-axis rotor current component is fixed at the rated value of the magnetizing current. At the instant $t=$ 
$50 \mathrm{~ms}$ a step on the reference $q$-axis rotor current is imposed. The results of Figure 7 show the current waveforms, Figure 8 shows the torque $M_{e m}$, the stator flux and $\sin \delta$ and Figure 9 shows the position and speed errors. One can see that the frequency is higher than $50 \mathrm{~Hz}$. The influence of the diodes commutation is clearly shown leading to a torque waveform with acceptable oscillations. However there is an error of frequency as shown in Figure 7-top and Figure 9.

\subsection{Using Also the D Rotor Adjustment System.}

Introducing the adjustment on the direct rotor current reference the results improve considerably. A PI with high bandwidth, similar to the bandwidth of the current controllers, was used.

Figure $\mathbf{1 0}$ shows that the torque ripple is comparable with that one of the first approach. Moreover $\sin \delta \approx 0$ i.e. the field orientation is achieved. Also the average frequency error in Figure 11 decreases to zero (i.e. the frequency now is $50 \mathrm{~Hz}$ ) and the stator flux tends to the rated flux.
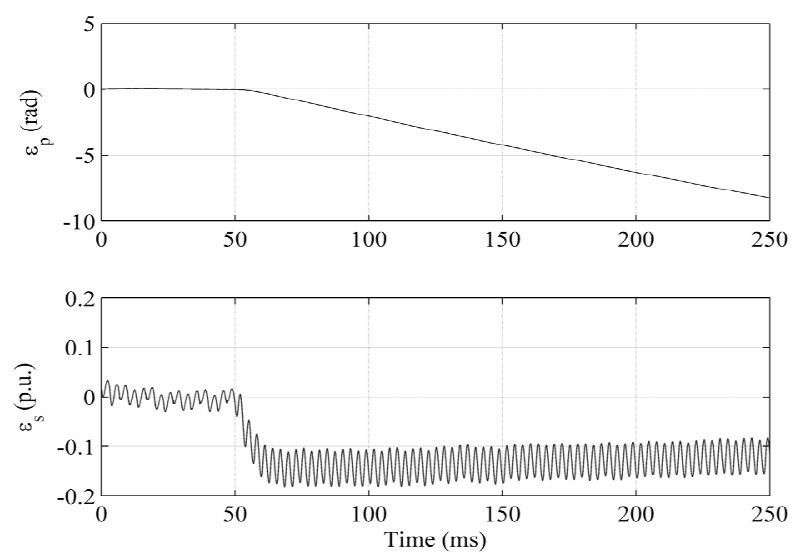

Figure 9. Position and speed errors.
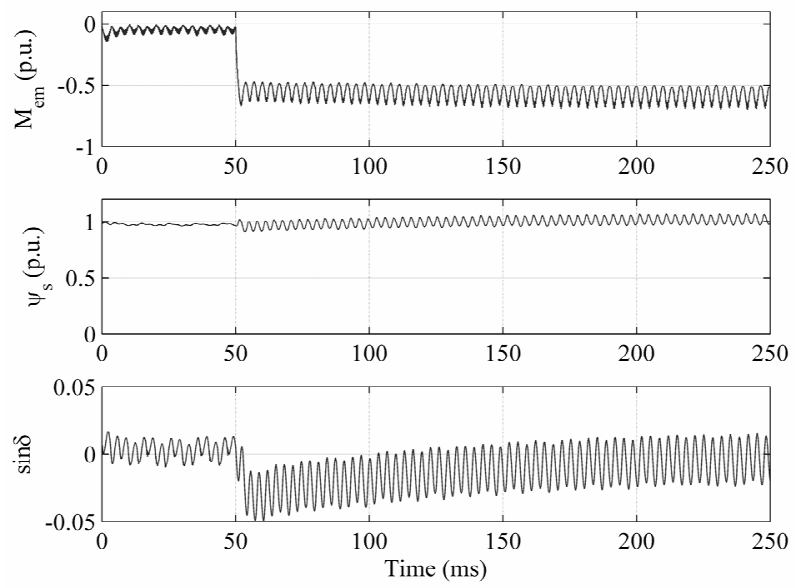

Figure 10. Torque, stator flux and $\sin \delta$.

\section{Experimental Results}

This section presents some experimental results obtained in a prototype using a $3.2 \mathrm{~kW}$ wound induction machine. The machine parameters are given in the Appendix. The control algorithm is implemented in Microchip dsPIC30F4011. To obtain experimental results in real time, four PWM output channels with simple RC filters were used. The actual rotor position is also measured using an encoder with a 4096 step resolution. A more detailed description of this prototype is found in [16]. Because the rated stator voltage is 3 times higher than the rated voltage of the rotor, a step down transformer ( $380 \mathrm{~V}$ to 220 V) was used between the stator and the diode bridge. The transformer introduces an additional equivalent stator leakage about $10 \%$ of the total leakage of the induction machine.

The voltage of the dc link was imposed by the dc network of the laboratory that was adjusted to $200 \mathrm{~V}$. This dc network is obtained with a dc generator rated to 40 $\mathrm{kW}$. Since the rated power of the rotor is smaller than the stator rated power, a small flux is used for this experimental validation. A value near 0.7 p. u. was chosen.

\subsection{Results of the First Approach}

Figure 12 shows the waveforms of the $d$-axis rotor current, of the stator voltages and of $\sin \delta$ when a step on the $d$-axis rotor current reference is imposed. Because this step is relatively small, the final voltage obtained is smaller than the voltage necessary to start current on the diode bridge. The machine is working at no-load. One can see that the voltage waveforms are almost sinusoidal as expected.

It is possible to conclude that the voltage response has good behavior being fast and without undesired transients.
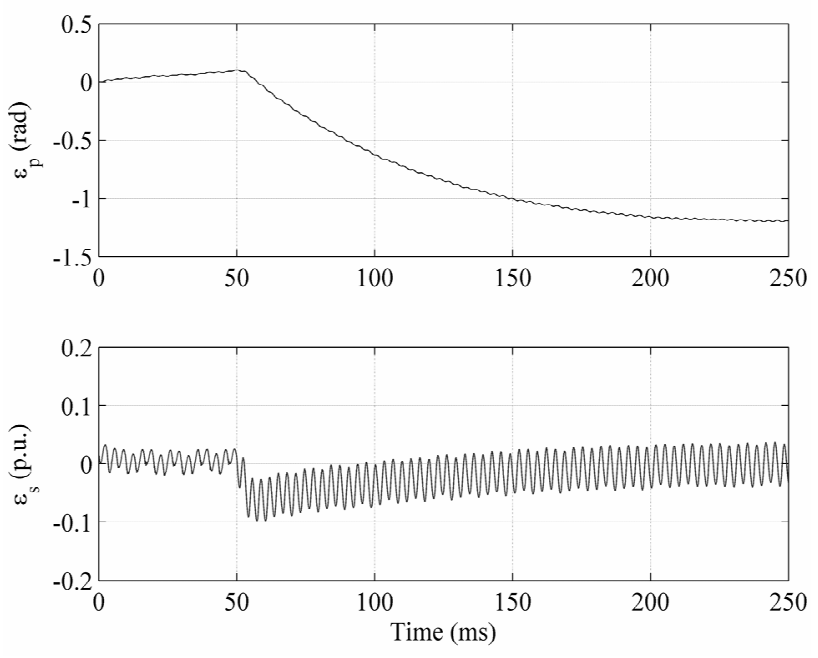

Figure 11. Position and speed errors. 
Figure 13 shows a different transient for a step on the $q$-axis rotor current. The system is working with constant $d$-axis rotor current reference ( 0.28 p.u.), and, at $t=50$ $\mathrm{ms}$ there is a step on the $q$-axis rotor reference current from $4 \%$ to $80 \%$. It is possible to conclude that the frequency is almost $50 \mathrm{~Hz}$, but $\sin \delta$ is not null, showing that the system is not working in field orientation. To have a better view of the stator voltage and current waveforms at steady state, Figure $\mathbf{1 4}$ is presented showing a zoom in time of Figure 13.

From Figure 14 it can be concluded that the waveforms have a relatively small harmonic content. It is also possible to verify that the phase shift between the voltage and the current is small (about $4 \mathrm{deg}$ ), as supposed in the section III-B.

\subsection{Results of the Second Approach}

Figure 15 shows a similar transient of Figure 13. In this case the $d$-axis rotor reference current is no longer a free
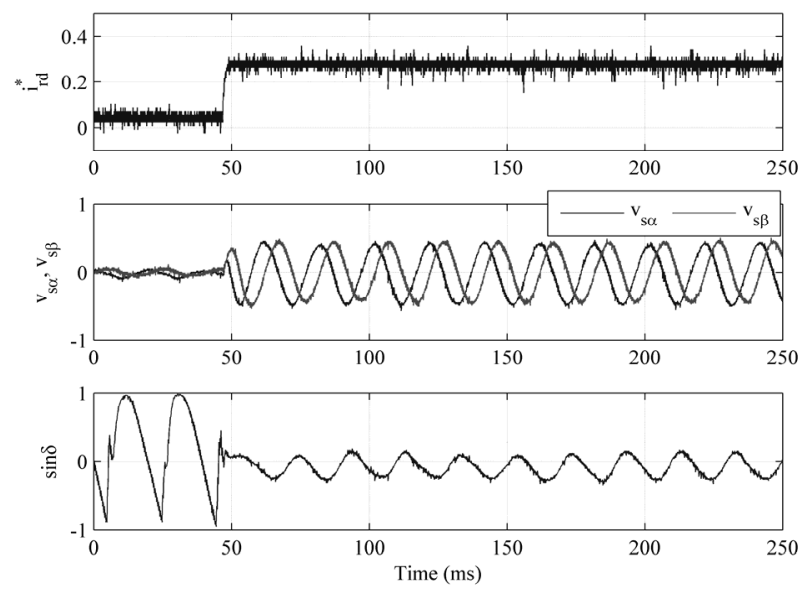

Figure 12. Response to a step on the $d$-axis rotor current at no-load.

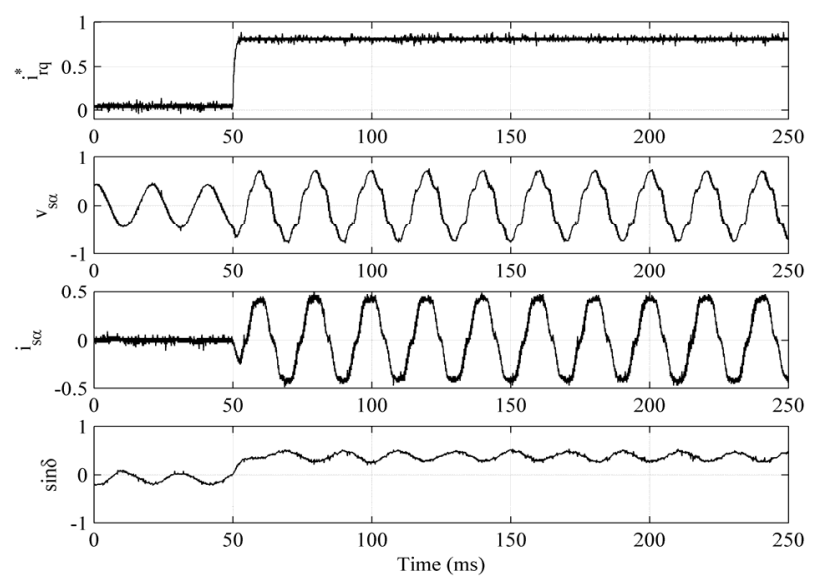

Figure 13. Response to a step on $q$-axis rotor reference current. The $d$-axis rotor reference current component is constant $\left(I_{d r}{ }^{*}=0.28\right.$ p.u. $)$
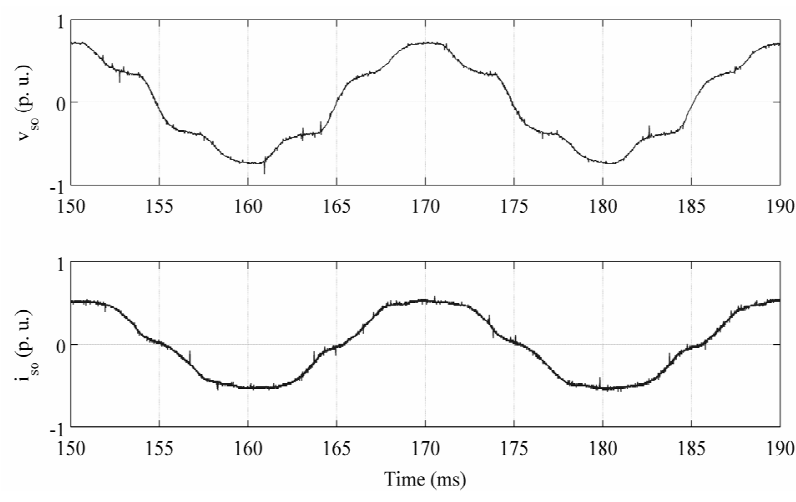

Figure 14. Steady state waveforms.
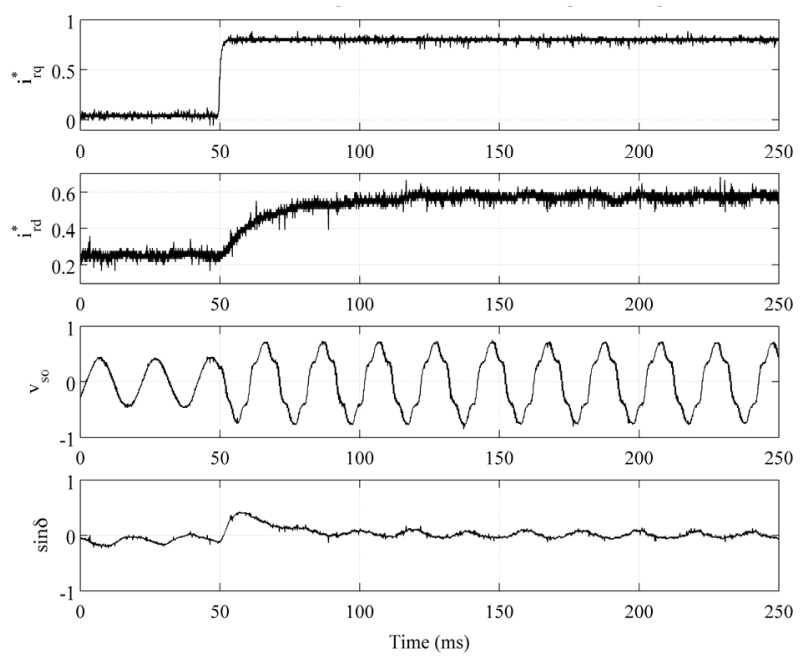

Figure 15. Response to a step on $i_{q}$ using also the adjustment of the $d$ rotor current reference.

quantity, because it is adjusted using a PI controller. It is possible to verify that the frequency is $50 \mathrm{~Hz}$ as desired, and that the $d$-axis rotor current reference is adjusted in order to obtain a $\sin \delta$ near zero. This variable is near zero before and after the transient.

\section{Conclusions}

The paper presents a control method for the DFIG connected to a dc link through a diode rectifier on the stator windings. Simulation and experimental results show that it is possible to drive the stator flux at the rated frequency of the machine using a simple controller that simultaneously adjusts the phase of the reference frame and the rotor $d$-axis current reference. The waveforms of the stator current are not sinusoidal, because the presence of the diode bridge, but have acceptable harmonic content.

\section{Acknowledgements}

This work was supported by national funds through FCT - Fundação para a Ciência e a Tecnologia, under project 
PEst-OE/EEI/LA0021/2011.

\section{REFERENCES}

[1] S. Chowdhury, S. P. Chowdhury and P. Crossley, "Microgrids and Active Distribution Networks," IET Renewable Energy series 6, The Institution of Engineering and Technology, 2009.

[2] J. A. Peças Lopes, C. L. Moreira and A. G. Madureira, "Defining Control Strategies for MicroGrids Islanded Operation," IEEE Transactions On Power Systems, Vol. 21, No. 2, 2006, pp. 916-924. doi:10.1109/TPWRS.2006.873018

[3] F. Blaabjerg, Z. Chen and S. B. Kjaer, "Power Electronics as Efficient Interface in Dispersed Power Generation System," IEEE Transactions Power Electronics, Vol. 19, No. 5, 2004, pp. 1184 -1194. doi:10.1109/TPEL.2004.833453

[4] F. Blaabjerg, R. Teodorescu, M. Liserre and A. V. Timbus, "Overview of Control and Grid Synchronization for Distributed Power Generation Systems," IEEE Transactions Industrial Electronics, Vol. 53, No. 5, 2006, pp.1398 -1409. doi:10.1109/TIE.2006.881997

[5] D. Salomonsson and A. Sannino, "Low-voltage DC Distribution System for Commercial Power Systems with Sensitive Electronic Load," IEEE Transactions Power Delivery, Vol. 22, No. 3, 2007, pp. 1620 -1627. doi:10.1109/TPWRD.2006.883024

[6] K. Kurohane, T. Senjyu, Y. Yonaha, A. Yona, T. Funabashi and C. H. Kim, "A Distributed DC Power System in an Isolated Island,” Proceedings IEEE ISIE, 2009, pp. 1-6.

[7] P. Karlsson and J. Svensson, "DC Bus Voltage Control for a Distributed Power System," IEEE Transactions Power Electronics, Vol. 18, No. 6, 2003, pp. 1405 -1412. doi:10.1109/TPEL.2003.818872

[8] Y. Ito, Y. Q. Zhong and H. Akagi, "DC Microgrid Based Distribution Power Generation System," Proceedings IPEMC, 2004, pp. $1740-1745$.
[9] H. Kakigano, Y. Miura, T. Ise and R. Uchida, "DC Micro-grid for Super High Quality Distribution-System Configuration and Control of Distributed Generations and Energy Storage Devices,” Proceedings IEEE Power Engineering Society Conference, 2006, pp. 1 -7.

[10] W. Leonard, “Control of Electrical Drives,” Berlin, Germany: Springer- Verlag, 1990.

[11] R. Pena, J. C. Clare and G. M. Asher, "Doubly Fed Induction Generator Using Back-to-back PWM Converters and Its Application to Variable-speed Wind-energy Generation,” Proceedings Inst. Electric Engineering -Electric Power Application, Vol. 143, No. 3, 1996, pp. 231-241. doi:10.1049/ip-epa:19960288

[12] G. Iwansky and W. Koczara, "DFIG-based Power Generation System with UPS Function for Variable-speed Applications," IEEE Transactions Industrial Electronics, Vol. 55, No. 8, 2008, pp. 3047-3054. doi:10.1109/TIE.2008.918473

[13] M. Hancock, "Rectifier action with Constant Load Voltage: Infinite Capacitance Condition,” Proceedings Inst. Electronics Engineering, London, UK, Vol. 120, No. 12, 1973, pp. 1529-1530.

[14] M. Bassetti, F. Braghin, F. Castelli-Dezza, M. F. Iacchetti and M. M. Maglio, "Energy Transfer on Rotating Shafts Using PM-Printed Winding Machine," IEEE International Conference on Electrical Machines 2012 ICEM '12, Marseille - France, September 2012.

[15] J. A. M. Bleijs, “Continuous Conduction Mode Operation of Three-phase Diode Bridge Rectifier with Constant Load voltage," IEE Proceeding Electronics Power Application, Vol.152, No.2, 2005, pp. 359-368. doi:10.1049/ip-epa:20040684

[16] G. D. Marques and D. M. Sousa, "Understanding the DFIG during Voltage Dips,” IEEE Transactions Energy Conversion, Vol. 27, No. 2, 2012, pp. 421-431.doi:10.1109/TEC.2012.2189214

\section{Appendix}

\section{Parameters of the $3.2 \mathrm{~kW}$ machine}

Induction Machine: stator $380 \mathrm{~V}, 8.1 \mathrm{~A}$, rotor $110 \mathrm{~V}, 19 \mathrm{~A}, 3.2 \mathrm{~kW}$, four poles, $1400 \mathrm{rpm}, L_{s}=1.62$ p.u., $M=1.17$ p.u., $r_{\mathrm{s}}=0.06$ p.u. $r_{r}=0.05$ p.u. 